\title{
THE EFFECTIVENESS OF KETOGENIC DIET IN TREATMENT OF EPILEPSY PATIENTS: A LITERATURE REVIEW
}

\section{Arif Hidayatullah" ${ }^{*}$, I Made Kariasa ${ }^{2}$}

1. Magister Student of Faculty of Nursing, Universitas Indonesia, Depok, Indonesia

2. Department of Medical-Surgical Nursing, Faculty of Nursing, Universitas Indonesia, Depok, Indonesia

* Correspondence: hidayatullaharif21@gmail.com

\begin{abstract}
The ketogenic diet is one of the alternative treatment management of epilepsy patients. The study aimed to examine the effect of the ketogenic diet for managing epilepsy patients. A literature review used by databases to find the relevant articles included Science Direct, Scopus, and Pro-Quest from 2011 to 2018. Metabolic therapy with the ketogenic diet can improve mitochondrial function, increase inhibition, and reduce nerve stimulation, which can cause seizures in epilepsy patients. Also, other factors need to be considered to produce an optimal impact on the use of the ketogenic diet, such as patient compliance and age. The ketogenic diet is one of the non-pharmacological alternatives that can be done to prevent recurrence in epilepsy patients.
\end{abstract}

Keywords: ketogenic diet, epilepsy, literature review

International Journal of Nursing and Health Services (IJNHS), September 2019, Volume 2, Issue 3; Page 39-44

Received: 04 April 2019; Revised: 23 April 2019; Accepted: 05 May 2019

DOI: http//doi.org/10.35654/ijnhs.v2i3.115

\section{Introduction}

Epilepsy is a transient event caused by excessive neuronal activity or inconsistency in the brain (1). That is a chronic neurological disease that can be experienced by all ages in both men and women (2). Based on data from the World Health Organization (WHO), the number of people living with epilepsy currently reaches 60 million peoples with an average prevalence of active epilepsy was 8.2 per 1000 population (2). Epilepsy has an impact on the quality of life. A previous study stated that the several effects of epilepsy included medical, psychological, social, and education (3). Schachter (2016) explained that the ketogenic diet significantly impacts for epilepsy management (4). The ketogenic diet used since 1921 is a diet high in fat, moderate protein, and low in carbohydrates. This combination of energy can cause ketosis, which serves to relieve seizures (5). The ketogenic diet has attracted the attention of researchers in the last 30 years (6). 
A study also showed the positive effect of the ketogenic diet for treating all types of epilepsy syndrome (7). Furthermore, the ketogenic diet showed a positive impact and safety for childhood and adolescent with epilepsy (8). Although the ketogenic diet was effective for long term care for epilepsy, however determining the efficacy of the ketogenic needed (9). This paper aims to analyze potential ketogenic diet as alternative treatment management of epilepsy patients.

\section{Method}

This paper is a literature review. The author used several databases included Webmail, Science Direct, Scopus, and Pro-Quest. The inclusion criteria of this study were 1) articles published from January 2010 to December 2018, 2) discuss management of epilepsy with the ketogenic diet. An exclusion criterion does not use language literature other than English. The keywords used in this study including; "ketogenic diet and epilepsy," "ketogenic diet," "epilepsy management." Twenty-eight articles selected including two cross-sectional methods, nine retrospective studies, four prospective observational methods, 1 case studies, one meta-analysis, nine quantitative true experiment method, one particular report, and one literature reviews.

\section{Results}

a. Theoretical Concept

The epilepsy is a common neurological disorder caused by abnormalities in the brain's electrical activity $(3,10)$. Schachter explains that there are several epilepsy management skills, which are long-term management; one of them is the consumption of ketogenic diets (4). The ketogenic diet is a high-fat, low protein, and low carbohydrates which induces the production of body ketones through fat metabolism, changing the primary calorie source of carbohydrates to fat (11). Whereas according to the Epilepsy Foundation, the ketogenic diet is a diet high in fat, moderate protein, and low in carbohydrates, which aims to make the body in a state of ketosis (12).

b. The ketogenic diet as alternative treatment management of epilepsy patients

Several studies have explained the clinical use of the ketogenic diet in metabolic processes in epilepsy patients (13). Previous studies showed the epigenetic effects on reducing the risk of permanent seizures due to a shift in the threshold in the process of seizures in epilepsy patients $(11,14)$. Besides, the ketogenic diet has caused DNA changes in gene expression seen in experimental models of epilepsy in the temporal lobe (15). Also, there is a definite therapeutic relationship between metabolism and neuron activity in the brain. Metabolic therapy with the ketogenic diet can improve mitochondrial function, increase inhibition, and reduce nerve stimulation, which can cause seizures in epilepsy patients (16).

c. The ketogenic diet as alternative treatment management of children, adolescents and adults patients with epilepsy

A ketogenic diet is a form of alternative medicine in patients with epilepsy who experience drug resistance. In children with epilepsy, the ketogenic diet is active and safe in preventing epileptic seizures (6,17-19). In adults with epilepsy, the ketogenic diet still needs further research. According to Aninditha \& Wiratman, the ketogenic diet is not 
effective in adult patients who have epilepsy. However, different from those reported by Maromi et al. in their study, which explains the ketogenic diet is an effective and beneficial alternative treatment in symptomatic epilepsy (9). Another study reveals that the ketogenic diet in adults with epilepsy is feasible, effective, and safe for the long term (20).

Providing the ketogenic diet to people with epilepsy can affect the digestive system, weight loss, and increased lipids in adults. Several side effects from the digestive system include constipation, diarrhea, and vomiting and can be solved by increasing the fiber intake, and sodium. Weight loss is a positive effect on overweight epilepsy patients. Increased serum fat is healthy with long-term ketogenic diet therapy (21-22). Some patients who discontinue diet therapy are not due to side effects caused by the ketogenic $\operatorname{diet}(24,25)$.

d. The ketogenic diet as alternative treatment management during pregnancy in epilepsy patients

Care for epilepsy in pregnant women needs to be done carefully (26). Concerning this issue, antiepilepsy drugs (AED) was non-pharmaceutical alternatives during pregnancy in epilepsy patients (27). The ketogenic diet in pregnant women with epilepsy has been shown to reduce blood ketone levels to moderate levels (26). A study mentioned that nonpharmacological epilepsy therapy such as the ketogenic diet could be useful during gestational age, although health care provider needs to monitor the side effects (27). Several studies explain the consideration of the benefits and potential losses to the fetus due to hyperketonemia conditions in epilepsy pregnant women. Thus, the ketogenic diet during pregnancy can be used as a non-pharmacological alternative (27).

e. Application of ketogenic diet as alternative treatment management in epilepsy patients

Some literature shows that the ketogenic diet in adults with epilepsy is comparable to children $(8,21)$. One prospective study showed the effectiveness of the ketogenic diet on reducing the frequency of seizures by $47 \%$ in the first and third months, and $33 \%$ in the next six months (13). So the Epilepsy Diet Center (AEDC) was formed in 2010 at Johns Hopkins Hospital to provide a ketogenic diet center for adults with epilepsy. The majority of patients attending AEDC are women, with ages ranging from 18 to 86 years. Overall, more than half of the participants who started the ketogenic diet continued to diet during the study. Of the 139 participants who began or continued diet therapy after the first visit, $41 \%$ (57 of 139) responded to diet therapy, and 27\% (37 of 139) became free of seizures (28).

The ketogenic diet provides long-term benefits that are effective in the treatment of epilepsy in adulthood and are a promising adjunct therapy for patients with drug-resistant epilepsy (28). The establishment of the Epilepsy Diet Center has proven beneficial for the epilepsy group and helps improve their diet. They need and access dietitians and neurologists in their care so that they can help improve compliance with the ketogenic diet (28).

\section{Discussion}

The management of the ketogenic diet can be used as a non-pharmacological alternative in the treatment of epilepsy patients (21). However, adequate information about the ketogenic diet and their side effects should be consent (5). In general, the side 
effects of the ketogenic diet are gastrointestinal and lipid complaints. However, the reported side effects are usually transient and are not the most common reason for patients to stop taking the ketogenic diet (29).

The ketogenic diet can be clinically significant by considering patient compliance. For increasing the effect of ketogenic diet therapy, several strategies carried out, such as evaluating health education, monitoring compliance, and awareness of epilepsy treatment, monitoring side effects, and developing friendly methods. The ketogenic diet is commonly used for children who have treated with antiepilepsy (28).

\section{Conclusions And Recommendations}

The ketogenic diet is one of the non-pharmacological alternatives that can be done to prevent recurrence in epilepsy patients. Metabolic therapy with the ketogenic diet can improve mitochondrial function, increase inhibition, and reduce nerve stimulation, which can cause seizures in epilepsy patients. Although it has benefits to prevent the recurrence of epilepsy, the ketogenic diet requires special attention to side effects that can occur in patients such as digestive problems. Also, other factors need to be considered to produce an optimal impact on the use of the ketogenic diet, such as patient compliance and age.

\section{Reference}

1. Rawlings GH, Brown I, Reuber M. Predictors of health-related quality of life in patients with epilepsy and psychogenic nonepileptic seizures. Epilepsy \& behavior. 2017 Mar 1; 68:153-8.

2. Trinka E, Kwan P, Lee B, Dash A. Epilepsy in Asia: Disease burden, management barriers, and challenges. Epilepsia. 2018 Jun 28.

3. Yeni K, Tulek Z, Simsek OF, Bebek N. Relationships between knowledge, attitudes, stigma, anxiety, and depression, and quality of life in epilepsy: A structural equation modeling. Epilepsy \& Behavior. 2018 Aug 1; 85:212-7.

4. Schachter SC. Optimal Care for Patients with Epilepsy: Practical Aspects, an Issue of Neurologic Clinics, E-Book. Elsevier Health Sciences; 2016 May 27.

5. Martin K, Jackson CF, Levy RG, Cooper PN. Ketogenic diet and other dietary treatments for epilepsy. Cochrane Database of Systematic Reviews. 2016(2).

6. Dozières-Puyravel B, François L, de Lucia S, Goujon E, Danse M, Auvin S. Ketogenic diet therapies in France: State of the use in 2018. Epilepsy \& Behavior. 2018 Sep 1; 86:2046.

7. Schoeler NE, Cross JH. Ketogenic dietary therapies in adults with epilepsy: a practical guide. Practical neurology. 2016 Jun 1;16(3):208-14.

8. Ye F, Li XJ, Jiang WL, Sun HB, Liu J. Efficacy of and patient compliance with a ketogenic diet in adults with intractable epilepsy: a meta-analysis. Journal of Clinical Neurology. 2015 Jan 1;11(1):26-31.

9. Cervenka MC, Henry BJ, Felton EA, Patton K, Kossoff EH. Establishing an adult epilepsy diet center: experience, efficacy, and challenges. Epilepsy \& Behavior. 2016 May 1;58:61-8.

10. Norsa'adah B, Zainab J, Knight A. The quality of life of people with epilepsy at a tertiary referral center in Malaysia. Health and quality of life outcomes. 2013 Dec; 11(1): 143.

11. Williams TJ, Cervenka MC. The role of ketogenic diets in epilepsy and status epilepticus in adults. Clinical neurophysiology practice. 2017 Jan 1; 2:154-60. 
12. Kossoff EH, Zupec-Kania BA, Amark PE, Ballaban-Gil KR, Christina Bergqvist AG, Blackford R, Buchhalter JR, Caraballo RH, Helen Cross J, Dahlin MG, Donner EJ. Optimal clinical management of children receiving the ketogenic diet: recommendations of the International Ketogenic Diet Study Group. Epilepsia. 2009 Feb;50(2):304-17.

13. Kossoff EH, Al-Macki N, Cervenka MC, Kim HD, Liao J, Megaw K, Nathan JK, Raimann X, Rivera R, Wiemer-Kruel A, Williams E. What are the minimum requirements for ketogenic diet services in resource-limited regions? Recommendations from the International League Against Epilepsy Task Force for Dietary Therapy. Epilepsia. 2015 Sep;56(9):1337-42

14. Benjamin JS, Pilarowski GO, Carosso GA, Zhang L, Huso DL, Goff LA, Vernon HJ, Hansen KD, Bjornsson HT. A ketogenic diet rescues hippocampal memory defects in a mouse model of Kabuki syndrome. Proceedings of the National Academy of Sciences. 2017 Jan 3;114(1):125-30.

15. Kobow K, Kaspi A, Harikrishnan KN, Kiese K, Ziemann M, Khurana I, Fritzsche I, Hauke J, Hahnen E, Coras R, Mühlebner A. Deep sequencing reveals increased DNA methylation in chronic rat epilepsy. Acta neuropathologica. 2013 Nov 1;126(5):741-56.

16. Masino SA, Rho JM. Metabolism and epilepsy: ketogenic diets as a homeostatic link. Brain research. 2019 Jan 15;1703:26-30.

17. Vehmeijer FO, van der Louw EJ, Arts WF, Catsman-Berrevoets CE, Neuteboom RF. Can we predict the efficacy of the ketogenic diet in children with refractory epilepsy?. European journal of pediatric neurology. 2015 Nov 1;19(6):701-5.

18. IJff DM, Postulant D, Lambrechts DA, Majoie MH, de Kinderen RJ, Hendriksen JG, Evers SM, Aldenkamp AP. The cognitive and behavioral impact of the ketogenic diet in children and adolescents with refractory epilepsy: a randomized controlled trial. Epilepsy \& Behavior. 2016 Jul 1;60:153-7.

19. Hallböök T, Sjölander A, Åmark P, Miranda M, Bjurulf B, Dahlin M. Effectiveness of the ketogenic diet used to treat resistant childhood epilepsy in Scandinavia. European Journal of Paediatric Neurology. 2015 Jan 1;19(1):29-36.

20. Kverneland M, Selmer KK, Nakken KO, Iversen PO, Taubøll E. A prospective study of the modified Atkins diet for adults with idiopathic generalized epilepsy. Epilepsy \& Behavior. 2015 Dec 1;53:197-201.

21. Klein P, Janousek J, Barber A, Weissberger R. Ketogenic diet treatment in adults with refractory epilepsy. Epilepsy \& Behavior. 2010 Dec 1;19(4):575-9.

22. Mosek A, Natour H, Neufeld MY, Shiff Y, Vaisman N. Ketogenic diet treatment in adults with refractory epilepsy: a prospective pilot study. Seizure. 2009 Jan 1;18(1):30-3.

23. Schoeler NE, Wood S, Aldridge V, Sander JW, Cross JH, Sisodiya SM. Ketogenic dietary therapies for adults with epilepsy: feasibility and classification of response. Epilepsy \& Behavior. 2014 Aug 1;37:77-81.

24. Payne NE, Cross JH, Sander JW, Sisodiya SM. The ketogenic and related diets in adolescents and adults-a review. Epilepsia. 2011 Nov;52(11):1941-8.

25. Ye F, Li XJ, Jiang WL, Sun HB, Liu J. Efficacy of and patient compliance with a ketogenic diet in adults with intractable epilepsy: a meta-analysis. Journal of Clinical Neurology. 2015 Jan 1;11(1):26-31.

26. Sussman D, van Eede M, Wong MD, Adamson SL, Henkelman M. Effects of a ketogenic diet during pregnancy on embryonic growth in the mouse. BMC pregnancy and childbirth. 2013 Dec;13(1):109. 
27. Martin-McGill KJ, Jackson CF, Bresnahan R, Levy RG, Cooper PN. Ketogenic diets for drug-resistant epilepsy. Cochrane Database of Systematic Reviews. 2018(11).

28. Cervenka MC, Henry BJ, Felton EA, Patton K, Kossoff EH. Establishing an adult epilepsy diet center: experience, efficacy, and challenges. Epilepsy \& Behavior. 2016 May 1;58:61-8.

29. Kessler SK, Neal EG, Camfield CS, Kossoff EH. Dietary therapies for epilepsy: future research. Epilepsy \& Behavior. 2011 Sep 1;22(1):17-22. 